\title{
The Mutual Role of Ability Emotional Intelligence and Trait Emotional Intelligence in Achieving Desired Objectives of Individual
}

\author{
R.B.L.Weragoda \\ Senior Manager \\ Sampath Bank PLC \\ Prof. H.H.D.N.P. Opatha \\ Senior Professor \\ Department of HRM \\ University of Sri Jayewardenepura
}

\begin{abstract}
The term Emotion broadly refers to elicit feeling of excitement (James, 1894). To elicit the feeling of excitement, mere unmediated perception is not sufficient, but some minimal cognitive thinking is needed (Brosch, 2013). However, contribution of cognitive thinking in experiencing emotion is debatable. Ability Emotional Intelligence (AEI) is recognized under the domain of intelligence (Brackett et al, 2011; Cherniss, 2010; Mayer et al, 2008, Mayer et al, 2000) and is defined as a type of cognitive capability (Kerr et al, 2006) while Trait Emotional Intelligence (TEI) is interpreted based on trait theory as persons' self confidence on emotional ability (Petrides, 2011; Petrides et al, 2007,). Mayer, et al, (2008) claimed that the term Trait is used typically to denote inherited characteristic and there is no justification for why certain traits are included. In contrast, Locke (2005) and Fineman (2004) argued that AEI is an invalid concept and does not belong to cognitive domain. In this study, the researchers have deviated from conventional argument that one concept is stronger than the other and explore how both constructs contribute from perceptual and ability perspectives in realizing desired objectives. According to self-efficacy theory, people with higher perceived value on their capabilities tend to initiate actions even under unfavorable conditions (Bandura, 1993). However Bandura (1977) further stressed that perceived self efficacy is not the sole determinant of behavior. Therefore, the researchers argue that both AEI and TEI are important in realizing desired objectives effectively and efficiently even though the constructs represent two different domains.
\end{abstract}

Key Words: Ability Emotional Intelligence, Trait Emotional Intelligence, Combined Impact

\section{Introduction}

The facts point in one direction: Your manager is highly satisfied with your performance and you received the highest performance appraisal rating during the last three consecutive years. Even though you have been working with the same momentum, your manager has given an unexpectedly lower rating for this year. You are quite shocked and disappointed. In the meantime, a new assignment offered by a competitor is in your hand. It is a perfect opportunity in terms of significant aspects i.e. salary and benefits, exposure to other areas and future opportunities for career upgrading. Yet, there is something that makes you worry about leaving 
from your current organization and colleagues who are much close to you. What are you going to do? Ignore the feeling and choose what appears to be the logical path, or go with your guts? Or, you may consider both your feelings and thoughts, derived from obvious facts, in order to make the decision? Resolving problems and making wise decisions considering both logical and emotional aspects are broadly referred as Emotional Intelligence (EI) (Brackett et al, 2011; Mayer and Salovey, 1997; Salovey and Mayer 1990).

The relationship between emotions and thought has been debated by philosophers for the last two millennia (Salovey and Grewal, 1993). Historically, emotion and intelligence were considered as being in opposition to one another (Lloyd, 1979). However, according to the theory of emotional intelligence, emotions make cognitive processes adaptive and individuals can think rationally about emotions (Brackett et al, 2011). The first theoretical model and definition on Ability Emotional Intelligence (AEI) was introduced about twenty years ago. According to the original definition, AEI was conceptualized as a set of related abilities (Mayer and Salovey 1997; Salovey and Mayer 1990). An alternative concept of Trait Emotional Intelligence (TEI) or Trait Emotional Self-efficacy, which is defined based on trait EI theory, was subsequently introduced (Mavroveli et al, 2009). TEI concerns people's perception of their own emotional abilities (Petrides, 2011) whilst AEI concerns emotions related to cognitive abilities. During the initial stage, there was a dramatic growth of the psychological literature concerning AEI ((Matthews et al, 2002). However, the concept of AEI has been criticized considerably in scholarly journals and in the popular press (Cherniss, 2010). Locke (2005) argued that EI is an invalid concept because it is not a form of intelligence and it is defined so broadly and inclusively that it has not embedded any understandable meaning. Further, Becker (2003) argued that Emotional Intelligence is an individual trait and it might just be the presence of high levels of the personality traits of agreeableness and extraversion. Furthermore, Fineman (2004) stressed that the concept of AEI is problematic and restrictive in terms of epistemological and phenomenological point of view. Moreover Petrides (2011) criticized that the term AEI is inconsistent with models of differential psychology and does not belong to domain of cognitive ability. In contrast, Mayer, et al, (2008), claimed that the term trait is used typically to denote inherited characteristic and there is no justification for why certain traits are included and others are not included to describe TEI. In this study, the researchers intend to deviate from contemporary argument that AEI is stronger than TEI or vis-à-vis and explore how both constructs contribute from perceptual perspective and ability perspective in achieving desired objectives. The Need of research in relation to AEI to actual behavior as opposed to self-reported behavior is stressed (Caruso et al, 2002; Brackett et al, 2006). The broad objective of the study is to examine the impact of TEI and AEI from perceptual and cognitive domains in realizing desired objectives of individuals. Moreover this study will propose a new construct of EI and research model which comply with nomological network, for further studies.

\section{Ability Emotional Intelligence}

AEI is defined as the "capacity to process emotional information accurately and efficiently, including that information relevant to the recognition, construction, and regulation of emotion in oneself and others" (Mayer and Salovey 1995, p. 197). The one important aspect of the above definition is that AEI is recognized as a person's ability in recognizing emotional information and carrying out abstract reasoning using such emotional information. Another feature of this 
definition is that AEI consists of conceptually related mental abilities. According to four-branch AEI model (Refer to Figure 1), these emotional abilities can be arranged as continuum flow from relatively lower level to higher level abilities (Mayer et al, 2008). These include the ability to (a) perceive emotion in oneself and others accurately, (b) use emotions to facilitate thinking (c) understand emotions, emotional language, and the signals conveyed by emotions, and (d) manage emotions so as to attain specific goals (Mayer and Salovey 1997). In estimating AEI levels of individuals, Mayer-Salovey- Caruso Emotional Intelligence Test (MSCEIT) is considered as one of the more comprehensive performance tests (Brackett et al, 2011). The sampling domain of MSCEIT is conceptualized based on the four-branch AEI model. As AEI is conceptualized as a distinctive mental ability, each ability branch of the model is measured by means of maximum performance tests similar to general intelligence test. AEI is a parallel term with other intelligences i.e. verbal comprehension, perceptual organization, visualization (Carroll, 1993). To categorize any construct as a form of intelligence, it should meet three stringent criteria: 1. Intelligence must reflect mental performance rather than behavioral attributes, 2. Intelligence should describe as a set of closely related abilities, 3. Intelligence should be able to develop with the age and experience. According to Salovey et al, (2000), AEI represents all the above requirements to be categorized under the domain of intelligence. Further they highlighted that AEI is an important member of domain in general intelligence and inclusion of AEI into domain of general intelligence will facilitate the improvement of general intelligence as a powerful predictor of important life outcomes.

The ability model addresses the ways in which emotions facilitate thinking processes. A person who manages emotions consciously will deliver more results than others (Mayer et al, 2008). The concept of AEI has already proven as one of the valuable additions to contemporary science and practice (Mayer et al, 2008) in terms of broadening the existing domain of human ability and predicting life outcomes from various aspects. With the introduction of the concept of Multiple Intelligence by Howard Gardner in 1983, theoretical attention was focused to explore specific intelligences. Studies done since 1990s have explored the possibility of having hot intelligences - intelligences that pertain to personally relevant information in addition to general intelligence (Mayer et al, 2008). Considering conceptual clarity of theory of AEI and empirical evidence already found, it has been substantiated that AEI plays an important role in diverse domains of human abilities. A more comprehensive understanding of the result of AEI related empirical studies facilitates relating of the construct with life outcomes. A number of studies substantiated that individuals with high AEI lead to gain positive outcome from various aspects of life. The following Exhibit demonstrates role of AEI in various aspects of life outcomes.

According to the above empirical evidence, it is indicated that AEI is a better predictor of important life-outcomes in diverse areas i.e. social relationship, workplace performance, and family life, mental and physical well-being. Mayer et al, in 2004 stressed that individuals with high AEI, most certainly can better perceive emotions, use them in thought, understand their meanings, and manage emotions better than others. Further they state that individuals with higher AEI tend to be somewhat higher in verbal, social, and other intelligences, especially if the individuals scored higher in the area of understanding emotions. Furthermore, the high AEI individual is more likely to have possessions of sentimental attachment around the home, workplace and to have more affirmative social interactions, particularly if the individuals scored highly on emotional management (Mayer et al, 2004). Such individuals may also be more 
capable in achieving desired goals, aims and missions than others. In summary, research on AEI during the last 20 years has substantiated that AEI plays a crucial role in achieving desired objectives in various aspects in real-life i.e. personal, family, academic, work performance etc as EI related abilities facilitate delivery of such outcomes effectively.

Figure 1: Graphical Representation of the Mayer-Salovey- Caruso Model of AEI

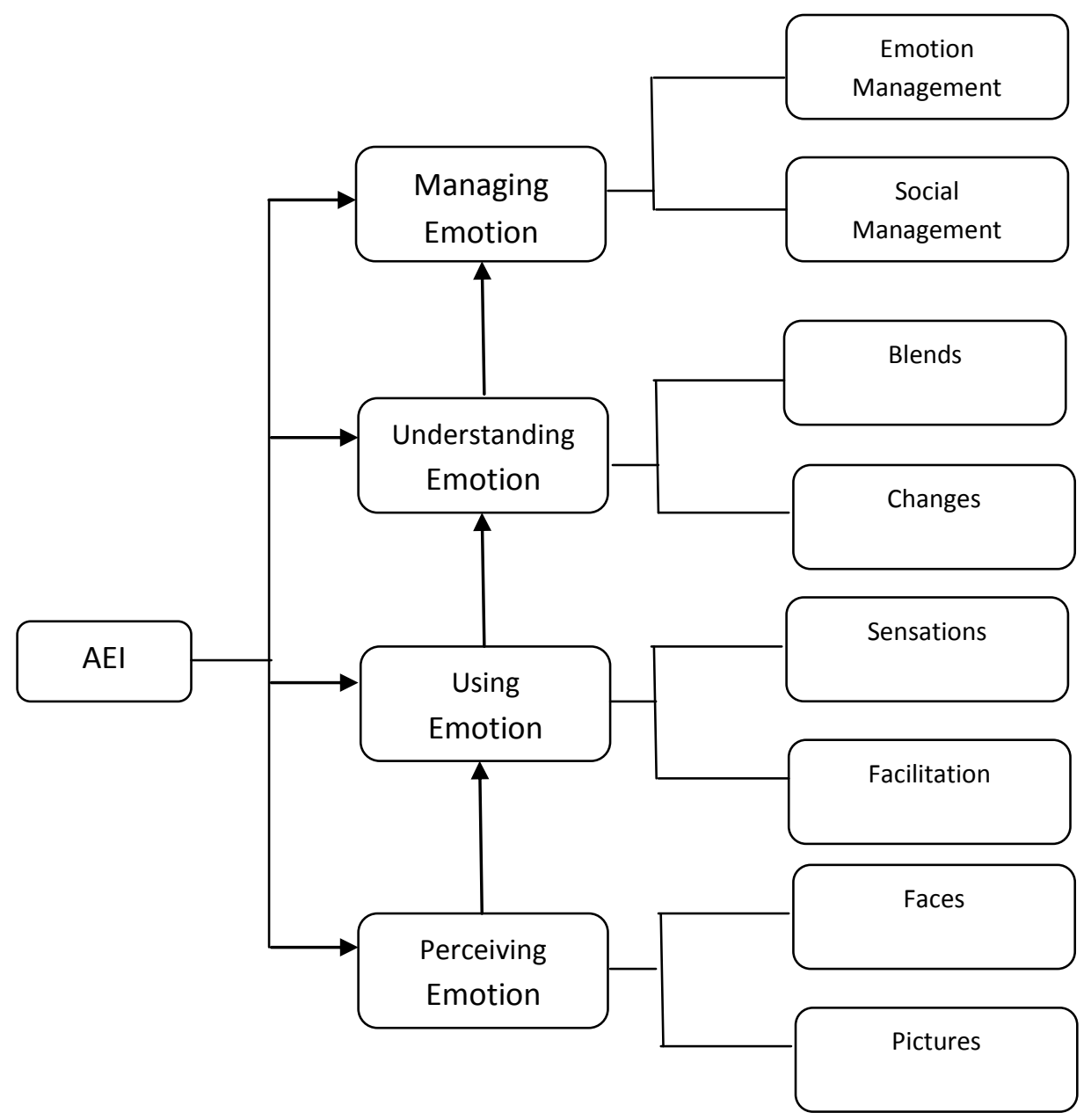

Source: Brackett et al, 2011 
Exhibit 1: Summary of selected study findings in AEI and its life outcomes

\begin{tabular}{|c|c|c|}
\hline Area & Research Finding & Representative Studies \\
\hline \multirow[t]{2}{*}{$\begin{array}{l}\text { Social } \\
\text { Relations }\end{array}$} & $\begin{array}{l}\text { Among children and adolescents, AEI } \\
\text { positively correlates with good social } \\
\text { relations and negatively correlates with } \\
\text { social deviance, measured both in and out } \\
\text { of school as reported by children } \\
\text { themselves, their family members and their } \\
\text { teachers. }\end{array}$ & Fine et al, (2003) \\
\hline & $\begin{array}{l}\text { Among adults, higher AEI leads to greater } \\
\text { self-perception of social competence and } \\
\text { less use of destructive interpersonal } \\
\text { strategies }\end{array}$ & Brackett et al, (2006) \\
\hline \multirow[t]{2}{*}{$\begin{array}{l}\text { Personal } \\
\text { Relations / } \\
\text { Psychological } \\
\text { well-being }\end{array}$} & $\begin{array}{l}\text { Others perceive high AEI individuals are } \\
\text { more pleasant to be around, more empathic, } \\
\text { and more socially adroit than those low in } \\
\text { AEI }\end{array}$ & Brackettt et al, (2006) \\
\hline & $\begin{array}{l}\text { AEI correlated with greater life satisfaction } \\
\text { and self-esteem and lower ratings of } \\
\text { depression; AEI also is correlated inversely } \\
\text { with some negative physical health } \\
\text { behaviors }\end{array}$ & Matthews et al, (2006) \\
\hline $\begin{array}{l}\text { Family } \\
\text { Relations }\end{array}$ & $\begin{array}{l}\text { AEI is correlated with some aspects of } \\
\text { family and intimate relationships as } \\
\text { reported by self and others }\end{array}$ & Brackett et al, (2005) \\
\hline \multirow[t]{2}{*}{$\begin{array}{l}\text { Academic } \\
\text { Performance }\end{array}$} & $\begin{array}{l}\text { AEI correlated with higher academic } \\
\text { achievements as reported by teachers, but } \\
\text { generally not with higher grades once IQ is } \\
\text { taken into account }\end{array}$ & Barchard (2003) \\
\hline & $\begin{array}{l}\text { AEI correlated with school grades and } \\
\text { intellectual problem solving }\end{array}$ & $\begin{array}{l}\text { Brackett and Mayer } \\
(2003)\end{array}$ \\
\hline $\begin{array}{l}\text { Work } \\
\text { Performance }\end{array}$ & $\begin{array}{l}\text { AEI correlated with more positive } \\
\text { performance outcomes and negations } \\
\text { outcomes in the laboratory and with more } \\
\text { success at work }\end{array}$ & Elfenbein et al (2007) \\
\hline
\end{tabular}


Even though AEI demonstrates a positive impact on real-life achievements in various aspects, it is worthwhile to question how ability based EI alone operates in situations where self perception on emotional capabilities of individuals is not up to the expected level. According to Bandura (1982), people do not behave optimally even though they know well what to do. Efficacious thinking plays a decisive role in-between knowledge and action as how people judge their capabilities and how through their self-perceptions of efficacy affect their motivation and behavior (Bandura 1982). Achieving desired objectives of individuals with higher AEI may partly be governed by self judgments on such abilities. Perceived self-efficacy is concerned with judgment of how well one can execute actions required to deal with prospective situations (Bandura, 1982). Therefore it can be argued that in addition to AEI, individual emotional selfefficacy plays an important role in achieving desired objectives.

\section{Trait Emotional Intelligence (Trait Emotional Self-efficacy)}

TEI refers to emotion related self-perceptions and behavioral dispositions relating to the perception, processing, and utilization of emotion-contained information (Petrides, 2011). One of the distinctive elements of the above definition compared with AEI is that TEI recognized emotions related self-perceptions via self-reported instruments, and belongs to the domain of self-efficacy. In contrast, AEI recognized cognitive-emotional ability via maximum performance test and belongs to the domain of cognitive ability. Therefore AEI and TEI are different constructs on the basis of the method of measurement used to operationalize them. However it is one of the common issues in the research related to EI that by ignoring the above conceptual differences, certain researches have used self-reported questionnaires and interpreted their findings with reference to concept of AEI (Petrides, 2011; Petrides and Furnham, 2003). Thus now it is generally accepted that TEI and AEI are different constructs and operationalization of one does not have implication on the other. The sampling domain of TEI consists of 15 noncognitive facets (Refer to Exhibit 2) related to personality traits. As TEI instrument assesses individual's self-perception on different facets of the sampling domain, trait EI theory provides a platform for the correct interpretation of perceptual data. It is important to note that although certain facets in the sampling domain of TEI were described as capabilities (Refer to Exhibit 2), self-rated perceptual values on respective facets were obtained at the time of administration of questionnaire.

Exhibit 2: The Sampling Domain of TEI

\begin{tabular}{|l|l|l|}
\hline No & Facets & Description \\
\hline 1 & Adaptability & Flexible and willing to adapt to new conditions \\
\hline 2 & Assertiveness & Forthright, frank, and willing to stand up for their rights \\
\hline 3 & Emotion expression & Capable of communicating their feeling to others \\
\hline 4 & $\begin{array}{l}\text { Emotional management } \\
\text { (Others) }\end{array}$ & Capable of influencing other people's feelings \\
\hline 5 & $\begin{array}{l}\text { Emotional perception } \\
\text { (Self and others) }\end{array}$ & Clear about their own and other people's feelings \\
\hline 6 & Emotion regulation & Capable of controlling their emotions \\
\hline 7 & Impulsiveness (Low) & Reflective and less likely to give in to their urges \\
\hline
\end{tabular}




\begin{tabular}{|l|l|l|}
\hline 8 & Relationships & Capable of maintaining fulfilling personal relationships \\
\hline 9 & Self-esteem & Successful and self-confident \\
\hline 10 & Self-motivation & Driven and unlikely to give up on the face of adversity \\
\hline 11 & Social awareness & Accomplished networks with superior social skills \\
\hline 12 & Stress management & Capable of withstanding pressure and regulating stress \\
\hline 13 & Trait empathy & Capable of taking someone else's perspective \\
\hline 14 & Trait happiness & Cheerful and satisfied with their lives \\
\hline 15 & Trait optimism & Confident and likely to look on the bright side of life \\
\hline
\end{tabular}

Sources: Petrides, 2011

According to Petrides et al, (2007), TEI is located at the lower levels of personality hierarchy. This aspect is important due to two reasons: (1) Concept of TEI can be linked with existing personality literature, (2) if impact of TEI factors is separated from personality domain, the variation of TEI can be isolated. Petrides et al, (2007) have isolated attributes of TEI from personality domain. Based on the above two empirical findings, it is clear that the relationship between TEI and personality model has already been established. A study done by Vernon et al, (2008), has established correlations between TEI and the Big-Five personality dimensions, primarily with genetic factors and secondarily with environmental factors. The implied meaning of the above empirical evidence is that genes contribute towards the development of individual differences in Big-Five personality types which are also responsible for the development of individual differences in TEI (Petrides et al, 2011). It is estimated that the heritable proportion of global TEI is around 40 percent, which is similar to the estimates obtained for other broad bandwidth personality traits (Johnson et al, 2008). Trait EI theory accepts the subjectivity of emotional experience and when it comes to predicting behavior, suitability of specific TEI profile will always depend on the context and type of behavior that seeks to be predicted (Petrides et al, 2007). Therefore higher TEI score should not necessary be relevant for individuals who are highly competent than individuals who are less competent. Therefore in predicting behavior, the suitability of particular profile of TEI depends on the context and type of behavior that expects to be predicted. The above empirical findings provide enough evidences to support the conceptualization of TEI as a part of the personality trait.

As TEI concerns individual's perceptions of their own emotional abilities, accuracy of self-rated perceptual measurements is questionable. Petrides and Furnham (2002) also accepted the above fact and further they have stated that accuracy of self-perceptions cannot be determined. Further they stressed that maximum performance measures of AEI cannot serve as an alternative benchmark for assessing the accuracy of perceptual measures. Thus, according to Bandura (1977), self-perceptions have a strong influence on cognition and behavior whether they are accurate or not. Further Bandura (1982) stressed that self-perception influences thought pattern, action and emotional arousal. However, accuracy of TEI measurements is not relevant in terms of comparison with AEI measurements as TEI is a set of self-belief measurement which represents perceptual domain. Other important learning point of the above finding is that there may be a significant numerical gap between self reports of ability and actual ability of EI as the two constructs measure values in two different domains.

Research on TEI has expanded significantly over the last few years (Mavroveli et al, 2009; Petrides, 2011). Recent research on children, adolescent and adult samples shows relationship 
between TEI and their prosocial and antisocial behavior, adaptive coping and depressive affect, leadership, happiness, emotion regulation, and affective decision-making (Petrides, 2011). The recent studies carried out by Petrides and Furnham in 2006, found that TEI is associated with lower levels of stress and higher levels of perceived job control, job satisfaction, and job commitment. Another study carried out in the area of healthcare showed that TEI had been impacted positively on self-rated physical health status (Tsaousis and Nikolaou, 2005). In the area of education also it shows that wide ranges of variables in relation to education are influenced by TEI (Petrides, 2011). Moreover it was found that high TEI facilitated pro-social and prevented antisocial behavior in children of primary school age (Petrides and Furnham, 2006). According to the above empirical evidence it is clear that TEI also plays a vital role in achieving desired objectives of individuals in various aspects i.e. personal, health, academic, work performance, social etc.

\section{Impact of Trait Emotional Intelligence on Ability Emotional Intelligence}

It is already empirically substantiated that AEI and TEI represent two different domains. However one's perception on his or her capacities- self-efficacy, affects cognitive processes from various aspects (Bandura (1993). According to Bandura, most of human behaviors are objective driven, purposive and influenced by self-appraisal of capabilities. Stronger the perceived self perception on capabilities the more challenging goals are set (Bandura, 1993). This mechanism directly enhances cognitive capabilities required to achieve desired objectives. Further, Bandura (1993) stressed that abilities are not a fixed attribute which can be further generated in numerous ways. Self-efficiency belief plays an important role in enhancing required cognitive capabilities of individuals. Moreover, Bandura in 1998 explained how selfefficacy affects cognitive ability of individuals. According to them, children who consider ability as an acquirable talent, set higher learning goals assuming that they can further improve required capabilities. Perceived cognitive self-efficacy affects memory capacity and memory performance of individuals both directly and indirectly by enhancing their cognitive effort (Bandura, 1993). Based on the above theoretical evidence, it can be argued that self-efficacy influences one's development of cognitive capabilities, individual's self-emotional efficacy (TEI) may influence development of AEI which is identified as a cognitive capability representing intelligence domain. Petrides (2011) identified 15 elements of the sample domain of TEI which include: emotional expression, emotional management (others), emotional perception (self and others), and emotion regulation with other 11 aspects (Refer to Exhibit 2). According to the four-branch model of AEI developed by Mayer and Salovey in 1997, the above four elements were identified as four dimensions of AEI. However, as TEI represents perceptual domain, it assesses individual's perception on the above four elements where AEI assesses individual's actual capabilities based on maximum performance assessment. While one model assesses individual's perception on the same elements, the other model assesses the individual's actual capacity. Based on the above conceptual relationship and Bandura's self-efficacy model, the researchers argue that individual's perception on the above four capabilities will influence actual performance levels of the same capabilities. Highly efficacious individuals seek challenges as a means for expanding knowledge and competencies (Bandura, 1993). Individual's TEI may influence directly and indirectly on their actual capabilities that include AEI also. 


\section{Impact of Ability Emotional Intelligence on Trait Emotional Intelligence}

According to the social cognitive theory, self-awareness, self-regulation, and self-control play a key role in developing individual's self-efficacy level (Bandura, 1997). Literature on AEI emphasizes the importance of self-awareness and self-regulation of emotions (Mayer and Salovey, 1995). Further a key aspect of self-awareness and self-management of emotions can lead to improve self-efficacy levels of individuals (Gundlach et al, 2003). This is the area of AEI and Self-efficacy that merge where self-efficacy refers in terms of self-awareness, regulation, and control manifesting in itself, while AEI emphasizes the specific self-awareness and regulation of one's own and others' emotional status. Further AEI enables to "perceive emotions, to access and generate emotions so as to assist to understand emotions and emotional knowledge, and to reflectively regulate emotions so as to promote emotional and intellectual growth" (Mayer and Salovey, 1997, p. 5). Furthermore according to attribution theory, cognition i.e. causal reasoning, can have a significant impact on assessment of self- efficacy levels of individuals (Gundlach et al, 2003). Moreover Gundlach et al argued that AEI enables individuals to interpret how their self-efficacy perceptions are shaped by their causal attributions. AEI should have an impact on self-efficacy through its influence on the causal reasoning processes. Beyond the impact of AEI on the causal reasoning processes associated with the development of selfefficacy, AEI can also shape self-efficacy directly by regulating emotional status. Accordingly, it can be argued that AEI as a cognitive construct influences one's perception on emotional capabilities through causal reasoning processes and directly regulating emotional status. Based on the above conceptual relationships, it can be argued that AEI as a cognitive construct influences how individual perceives his or her emotional capabilities.

\section{Reciprocal Effect of TEI and AEI in Achieving Desired Objectives}

The above discussion of the literature on TEI and AEI provides a basis to understand the symbiotic relationship between the above two constructs. However, it is important to clarify conceptual boundaries of the above two constructs in order to recognize the degree of influence from each other in achieving desired goals. As TEI refers individual's perception on his or her emotional capabilities, the foundation of the TEI derived from the concept of self-efficacy, which was developed by Bandura (1993) based on Social Cognitive Theory. According to selfefficacy theory, people who have higher perceived value (higher self efficacy) on their capabilities tend to initiate actions even in unfavorable conditions in order to realize desired objectives (Bandura, 1993). Further Bandura stressed that a strong sense of self-efficacy enhances accomplishment of personal goals in many ways: Individuals with high self-efficacy considered difficult task as challenges to be mastered rather than as threats to be left out. They set challenging goals and foster strong commitment until they realize such goals. They consider reasons for failures as their own insufficient effort or skills or knowledge. Hence individuals with same skill level may demonstrate different achievement levels in realizing desired goals depending on their different self-efficacy levels. As an example, Collins (1982) did a study with children who had different mathematical abilities - low, medium, and high and observed that at each level of ability children who believed strongly in their capabilities perform better than others. Finally she concluded that people who perform poorly may do so because they lack the skills or they have the skills but they lack the sense of efficacy to use them well. This means that in certain instances, individuals are unable to achieve desired goals not really due to lack of 
abilities but due to lack of efficacious thinking on their abilities required to achieve desired goals. However according to Bandura (1993) ability is not a fixed attribute rather it is a generative capability with high perceived value. Moreover he stressed that the individuals with high self-efficacy seek challenges that provide them opportunity to expand their abilities.

It is already empirically proven that the individuals with high TEI have more tendencies in achieving desired goals. Emotion expression, emotional management, emotional perception and emotion regulation are the four important elements in the sample domain of TEI (Refer to Exhibit 2). Individuals with high self-perception on emotion expression, emotional management, and emotion regulation are assumed to be high TEI individuals who are tenacious in achieving desired goals. Therefore it can be argued that individuals with higher TEI may have more tendencies in attending to actions required to achieve desired objectives. However Bandura (1977) further stressed that perceived self-efficacy is not only the sole determinant of effective behavior and high performance. Efficacious thinking alone will not produce desired results if required capabilities do not exist. In terms of emotional intelligence, it can be argued that perceived emotional capabilities (TEI) alone will not produce desired results in achieving desired goals and it should be accompanied with EI skills as defined based on ability based EI model. On the other hand, ability based EI alone may not be effective in situations where self perception on emotional capabilities is not up to the expected level. Finally it can be argued that even though both TEI and AEI individually influence achievement of desired objectives of individuals, degree of success will be limited in situation where one construct is lower than the other construct. Therefore it is more appropriate to consider mutual impact of both constructs rather than considering individual impact of each construct. Most importantly, according to the above conceptual linkages explained, one construct facilitates the development of the other construct and that one construct alone will restrict influence of achievement of desired objectives. Individual's perception on emotional capabilities will facilitate the development of cognitive abilities of emotion i.e. perceive, use, understand and management of emotions and vis-à-vis. On the other hand, impact of one construct can be further enhanced by the other construct. Based on this new conceptual relationship, the researchers propose a new EI construct which represents both AEI dimensions and TEI dimensions. As the new construct represents both perceptual domain and ability domain of EI, it will be more meaningful and strong in terms of influencing achievement of desired objectives.

Figure 2: $\quad$ A Novel Research Model

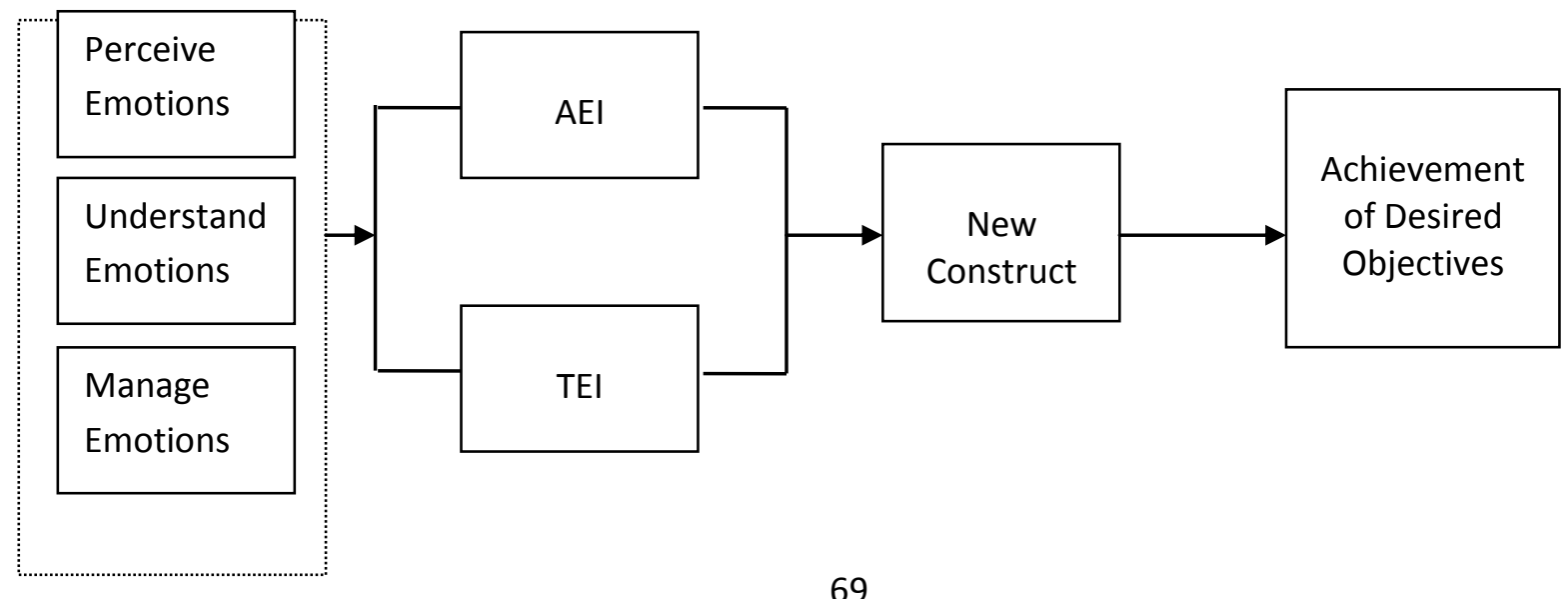


According to the Mayer and Salovey AEI model (1997), there are four branches: perceive emotion in oneself and others accurately, use emotions to facilitate thinking, understand emotions and manage emotions so as to attain specific goals. However, Mayer et al, did a study in 2000 to assess the empirical validity of the four branches of EI model and to clarify the factor structure of EI. According to the results of exploratory factor analysis of the study, factors were loaded into three portions: perception, understanding and managing emotions, and two factors: assimilation and understanding were highly inter-correlated $(\mathrm{r}=0.87)$ and therefore difficult to distinguish each other (Mayer et al, 2000). According to the above findings, there are three key EI branches in the proposed research model. As discussed in the above sections, the impact of three EI branches will be assessed through both perceptual measurement (TEI) and ability measurement (AEI). Even though Petrides (2011) argued that correlation between measures of TEI and AEI is low, number of researchers stressed that a well-designed self-efficacy measure of EI may correlate more strongly with performance measures (eg. Bandura, 1997, Bandura 1977, Brackett et al, 2006). However, the researchers believe that whether AEI measures correlate with TEI measures is not relevant for the proposed research model, as the model highlights the importance of both constructs in realizing desired objectives. Therefore the new construct represents both TEI dimensions and AEI dimensions of EI as both aspects are important in terms of achieving desired objectives. In this model it is argued that individual differences in AEI or TEI do not provide a complete explanation as to why individuals differ in their level of achievement of desired objectives. More specifically, it is argued that differences in individual performance can be explained by mutual impact of AEI and TEI than individual values of such constructs. Therefore we argue that the new construct which represents perceptual aspects as well as ability aspects of EI, will influence achievement of desired objectives more effectively than the previous models as both perceptual EI and ability EI mutually and individually influence the achievement of desired objectives.

\section{Conclusion and Future Directions}

As discussed in the above sections, the objective of the study is to ascertain impact of AEI and TEI on achieving desired objectives. The cognitive, physiological and behavioral changes associates with emotional responses which are adaptive and can be further developed in achieving important life outcomes according to the theory of EI (Brackett et al, 2011). According to the theory of trait emotional intelligence, TEI may be beneficial in some context but not in other contexts and accept the subjectivity of emotional experience (Petrides et al, 2007). Irrespective of the conceptual deviations between AEI and TEI, the present study elaborates how AEI from cognitive perspective and TEI from perceptual point of view influence achievement of desired objectives of individuals.

Think back to the scenario that opened this research paper. You should decide whether to accept the new assignment or retain in the current organization irrespective of frustration and disappointment created due to lower appraisal rating given by your manager. As a result of unexpected lower appraisal rating some individuals may become totally disappointed and tend to decline further. In contrast certain individuals may consider that receiving lower appraisal rating is a challenge to earn higher appraisal rating at the next time and decide to improve current performance status further. The researchers argue that differences in AEI or TEI alone do not provide a complete explanation for the above two different behaviors. Your perception on your 
capabilities or your actual capabilities along is not sufficient to achieve superior appraisal rating at the next time. Individuals with high self-efficacy on capabilities are unable to achieve desired objectives in situations where their actual capabilities are not sufficient (Bandura, 1977). Most importantly the researchers argue that mutual impact of AEI and TEI is more vital than isolated impact of TEI and AEI in achieving desired objectives. The new construct which includes both dimensions of TEI and AEI is effective in terms of achieving desired objectives as mutual impact of both construct is considered. In summary, the mutual influence of AEI and TEI in achieving desired objectives proposes a new dimension on emotional intelligence which can be improved by developing interventions that relate to enhance capabilities and self-efficacy of three branches of the proposed model: perceive emotions, understand emotions and manage emotions.

Integrating two different constructs together, this study facilitates the expansion of contemporary boundaries of the emotional intelligence. However in order to utilize the power of the new construct there are certain conceptual and empirical gaps to be filled. Therefore it is proposed to focus future studies on emotional intelligence and new construct in following three areas: 1. Empirical studies on how and to what extent AEI influences on TEI and vice versa. The above findings will help identify most critical dimensions of the constructs in terms of improving mutual impact. 2. Develop instruments with required psychometric properties to measure the behavior of the new construct. This aspect is important in applying the new construct in real life scenarios and practitioners who need to quantify impact of the mutual construct. 3. How the new construct influences and predicts various life outcomes mainly on organizational performance and individual performance. Although research in this area is still at the beginning of the learning curve, what we have learnt thus far is promising: there is a mutual impact between AEI and TEI, it predicts important life outcomes and such skills can be further developed.

\section{References}

Bandura, A. (1982), Self-efficacy mechanism in human agency, American Psychologist, Association, Vol. 37, No. 2, pp. 122-147.

Bandura, A. (1977), Self efficacy: Toward a unifying theory of behavioral change, Psychological Review, Vol. 84, No. 2, pp. 191-215.

Bandura, A. (1993), Perceived self efficacy in cognitive development and functioning, Educational Psychology, Vol. 28, No. 3, pp. 117-148.

Bandura, A. (1998), Self-efficacy, Encyclopedia of mental health, San Diego: Academic Press.

Barchard, K. A. (2003), Does emotional intelligence assist in the prediction of academic success?, Educational and Psychological Measurement, Vol. 63, pp. 840-858.

Becker, T. (2003), Is emotional intelligence a viable concept?, Academy of Management Review, Vol. 28, No. 2, pp. 192-205.

Brackett, M. A., Rivers, S. E. and Salovey, P. (2011), Emotional Intelligence: Implications for personal, social, academic and workplace success, Social and Personality Psychology Compass, Vol. 5, No. 1, pp. 88-103. 
Brackett, M. A., Rivers, S. E., Shiffman, S., Lerner, N. and Salovey, P. (2006), Relating emotional abilities to social functioning: A comparison of self-report and performance measures of emotional intelligence, Journal of Personality and Social Psychology, Vol. 91, No. 4, pp. 780-795.

Brackett, M. A., Warner, R. M. and Bosco, J. (2005), Emotional intelligence and relationship quality among couples, Personal Relation, Vol. 12, pp. 197-212.

Brackett, M. A. and Mayer, J. D. (2003), Convergent, discriminant, and incremental validity of competing measures of emotional intelligence, Personality and Social Psychology Bulletin, Vol. 29, pp. 1147-1158.

Brosch, T. (2013), On the role of appraisal processes in the construction of emotion, Emotion Review, Vol. 5, No. 4, pp. 369-373.

Carroll, J. B. (1993), Human cognitive abilities: A survey of factor analytic studies, New York: Cambridge University Press.

Caruso, D. R., Mayer, J. D. and Salovey, P. (2002), Relation of an Ability Measure of Emotional Intelligence to Personality, Journal of Personality Assessment, Vol. 79, No. 2, pp. 306320.

Cherniss, C. (2010), Emotional intelligence: toward clarification of a concept, Journal of Industrial and Organizational Psychology, Vol. 3, pp. 110-126.

Collins, V. L. (1982), Self-efficacy and ability in achievement behavior, Paper presented at the annual meeting of the American Educational Research Association, New York, As cited by Bandura, A. 2003.

Elfenbein, H. A., Der Foo., M. D., White, J. and Tan, H. H. (2007), Reading your counterpart: the benefit of emotional recognition accuracy for effectiveness in negotiation, Journal Nonverbal Behavior, pp. 1-19.

Fine, S. E., Lzard, C. E., Mostow, A. J., Trentacosta, C. J. and Ackerman, B. P. (2003), First grade emotion knowledge as a predictor of fifth grade self-reported internalizing behaviors in children from economically disadvantaged families, Development Psychopathology, Vol. 15, pp. 331-342.

Fineman, S. (2004), Getting the measure of emotion-and the cautionary tale of emotional intelligence, Human Relations, Vol. 57, No. 6, pp. 719-740.

Gardner, H. (1983), Frames of Mind: The theory of multiple intelligence, New York: Basic Book.

Gundlach, M. J., Martinko, M. J. and Douglas, S. C. (2003), Emotional intelligence, Causal reasoning, And The self-efficacy development process, The International Journal of Organizational Analysis, Vol. 11, No. 3, pp. 229-246.

James, W. (1894), The physical basis of emotion, Psychological Review, Vol. 1, pp. 516-529. 
Johnson, A. M., Vernon, P. A. and Feiler, A. R. (2008), Behavioral genetic studies of personalty: An introduction and review of the results of 50+ years of research, Handbook of Personality and Testing, Sage Publishers, Canada.

Kerr, R., Garvin, J., Heaton, N. and Boyle, E. (2006), Emotional Intelligence and leadership effectiveness, Leadership and Organization Development Journal, Vol. 27, pp. 265-279.

Lloyd, A. C. (1979), Emotion and decision in stoic psychology, The Stoics, Los Angeles: University of California Press.

Locke, E. A. (2005), Why emotional intelligence is an invalid concept, Journal of Organizational Behavior, Vol. 26, pp. 425-431.

Matthews, G., Zeidner, M. and Roberts, R. D. (2002), Emotional intelligence: Science and Myth, Cambridge: MIT Press.

Matthews, G., Emo, A. K., Funke, G., Zeidner, M. and Roberts, R. D. (2006), Emotional intelligence, personality, and task-induced stress, Journal of Experimental Psychology Applied, Vol. 12, pp. 96-107.

Mavroveli, S., Petrides, K. V., Sangareau, Y. and Furnham, A. (2009), Exploring the relationship between trait emotional intelligence and objective socio-emotional outcomes in childhood, British Journal of Educational Psychology, Vol. 79, pp. 259-272.

Mayer J. D., Salovey, P. and Caruso, D. (2000), Models of emotional intelligence, Handbook of intelligence, Cambridge: Cambridge University Press.

Mayer, J. D., Salovey, P. and Caruso, D. R. (2004), Emotional Intelligence: theory, findings, and implications, Psychological Inquiry, Vol. 15, No. 3, pp.197-215.

Mayer, J. D. and Salovey, P. (1995), Emotional intelligence and the construction and regulation of feelings, Applied and Preventive Psychology, Vol. 4, pp. 197-208.

Mayer, J. D. and Salovey, P. (1997), What is emotional intelligence? Emotional development and emotional intelligence: Implication for education, New York: Basic Book.

Mayer, J. D., Caruso, D. R. and Salovey, P. (2000), Emotional intelligence meets traditional standards for an intelligence, Intelligence, Vol. 27, No. 4, pp. 267-298.

Mayer, J. D., DiPaolo, M. T. and Salovey, P. (1990), Perceiving affective content in ambiguous visual stimuli: A component of emotional intelligence, Journal of Personality Assessment, Vol. 54, pp.7 72-782.

Mayer, J. D., Roberts, R. D. and Barsade, S. G. (2008)a, Human abilities: Emotional intelligence, Annual Review of Psychology, Vol. 59, pp. 507-536.

Petrides, K. V. (2011), Ability and trait emotional intelligence: The Wiley-Blackwell Handbook of Individual Differences, Blackwell Publishing Ltd. 
Petrides, K. V., Gonzalez, J. C. and Furnham, A. (2007), On the criterion and incremental validity of trait emotional intelligence, Cognition and Emotion, Vol. 21, pp. 26-55.

Petrides, K. V. and Furnham, A. (2003), Trait emotional intelligence: Behavioral validation in two studies of emotion recognition and reactivity to mood induction, European Journal of Personality, Vol. 17, pp. 39-57.

Petrides, K. V. and Furnham, A. (2006), The role of trait emotional intelligencer in a gender specific model of organizational variables, Journal of Applied Social Psychology, Vol. 36, pp. 552-569.

Salovey, P. and Mayer, J. D. (1990), Emotional intelligence, Imagination, Cognition and Personality, Vol. 9, pp. 185-211.

Tsaousis, I. and Nikolaou, I. (2005), Exploring the relationship of emotional intelligence with physical and psychological health functioning, Stress and Health, Vol. 21, pp. 77-86.

Vernon, P. A., Vilani, V. C., Schermer, J. A. and Petrides, K. V. (2008), Phenotypic and genetic association between the Big Five and trait emotional intelligence, Twin Research Human Genetics, Vol. 11, pp. 524-530. 